\title{
Development of an Activity Format to Support Exchange Students in ASEAN Community
}

\author{
Tiamyod Pasawano
}

\begin{abstract}
The objectives of this study are 1) to study a format of an activity for support an exchange students in ASEAN community. 2) To development a model of an activity for support an exchange students in ASEAN community, and 3) to present a format of an activity for support an exchange students in ASEAN community. The samples used in the study were 15 students of Bachelor degree year 4 in major of educational technology and communications, Faculty of Technical Education, Rajamangala University of Technology Thanyaburi, Pathum Thani, Thailand. The research instruments included a questionnaires for specialist assessment, a format of an activity for support an exchange students in ASEAN community, and the questionnaires on students' satisfaction in learning with a prototype of model. The statistics used in the research were percentage, mean, standard deviation and t-test for dependent sample. The finding found that the format of an activity for support exchange students in ASEAN community for students of Bachelor Degree year 4 in major of educational technology and communications has the efficiency of $81.50 / 80.23$ in average based on the standard. The students' learning achievement after using the model was higher than that of the pretest: 21.37 S.D. 3.02 while the average of the posttest was 39.57 S.D. 3.07 and the t-test between the pre- and posttests were 57.54 which had a significant difference at the 0.05 level. The satisfaction of the students towards a format of an activity for support an exchange students in ASEAN community for students of bachelor degree year 4 in major of educational technology and communications had an average of 4.70 which was at a very high level.
\end{abstract}

Index Terms - Activity format, Exchange students, ASEAN community, Educational technology .

\section{INTRODUCTION}

The human resource development in education is really important and needs to be developed because it is a skill in needed for a career as everyone in a family can generate income and be self-reliant. According to a study of economic cooperation of the six countries in the Greater Mekong Sub-region, the objectives are to promote trade, investment, agriculture and services to promote employment and raise the standard of living of people in the area. It also helps promote and develop cooperation in technology and education as well. As a result, the study showed the field that were in high potential for development and cooperation which were human resources development, work based skills development, education and

Tiamyod Pasawano, Rajamangala University of Technology Thanyaburi, Faculty of Technical Education, Department of Educational Technology and Communications, Thanyaburi, Pathum Thani, 12110, Thailand public health. As the advantage of this cooperation, it provides the expansion of Thailand's industrial and service administration widely and openly. It covers training course, academic exchange, research and development, and government policy on supporting the building of educational institutions as well as other training institutions. This demonstrates Thailand's role in linking the neighboring countries with a network of education, training and research in the sub-region so as to increase the potential and continue the mission of education for maximum efficiency. (Office of the National Economic and Social Development Board, 2014).

The changes that will take place in the near future will be labor mobility. It needs to be adapted to the fast changing world, such as language training and professional expertise in order to increase the value of self-employment in the ASEAN market. For instance, if we are leaders in the field of craftsmanship, it will be an advantage to become a mentor in the field of vocational skills for the ASEAN community. It is a great opportunity to create a plan for paving the way for graduates to have a career in their field. It also helps to create awareness and attitude towards ASEAN countries to be work cooperatively in the future.

The researcher was invited to be a guest lecturer at various countries in the region such as at the National University of Laos. Mean Chey University of Cambodia, and Yangon University. Of Myanmar. Through the interaction and observation $50 \%$ of students can listen and speak Thai fluently and know style of living of Thai people as they learn Thai language through Thai TV. This shows that they know Thailand clearly except we do not know them as a neighboring country. It would cause problems in the future, if students graduated and find work together across the countries. This will affect their working condition.

In this study, the focus is on the exchange of knowledge, sharing culture which will be interacting from friends to friends within the training including the pursuit of activities that they can do together so as to build love and unity among ASEAN member countries. According to the results from a pilot study, four Cambodian students from Mean Chey University, Mean Chey province Cambodia who came to study at Faculty of Technical Education, Rajamangala University of Technology Thanyaburi, Pathum Thani Province on November 12, 2013 to February 12, 2014 showed that Thai students were less likely to be excited about acquiring foreign students from nearby countries and were not enthusiastic to practice listening 
or speaking Cambodian language while Cambodian students tired walking towards Thai students to practice speaking and writing Thai and learnt ways of life in Thailand. In this case, there is no clear conclusion as to why, but it can be included by the reason that "know yourself, but do not know other clearly". This is the reason for continuing the student exchange program, which will be extended to other countries such as Lao PDR, Myanmar, Vietnam, Indonesia, Singapore, and Malaysia as to cover all the questions that remain unanswered in the pilot program mentioned above.

\section{A. Purpose of the study}

1. To study a format of an activity for support an exchange students in ASEAN Community.

2. To develop a format of an activity for support an exchange students in ASEAN community.

3. To present a format of an activity for support an exchange students in ASEAN community

\section{B. Scope of the study}

The population in this study consisted of year 3 and year 4 students of Faculty of Technical Education which were selected using purposing sample resulted in 15 students.

The scope of the contents were based on the academic literature, the Internet courses and tutorials of ASEAN countries which prepare students to enter the labor market in the ASEAN Community.

ASEAN in this study cover research analysis using Cambodia, Laos, Myanmar, Vietnam, Indonesia and Thailand as the basis for information seeking.

\section{MethodOLOGY}

\section{A. Research Phase 1:}

Study the student activities model to promote student exchange study theories and related research regarding how to exchange knowledge, sharing culture, transfer learning activity with Knowledge Management and Collaborative learning used to achieve the objective.

\section{B. Research Phase 2}

study on the development an activity model after summarizing the results of the activities and opinions, and results of the brainstorming sessions with the experts. Then, process data analysis and draft the format of activities.

Research Phase 3: trial experiment formulated the experimental activity. The samples used were purposive sampling which assigned to 15 students from 4 universities in ASEAN (only the target universities that support this research study). It comes from the same specific sampling by providing students in ASEAN to do activities together at the Faculty of Technical Education 2 days to participate in the exchange activities held, study the observation, study the satisfaction assessment, and analyze the Means score and Standard Deviation (S.D.)

\section{RESULTS}

The researcher conducted the data analysis as the following:

a. Establish the effectiveness of the activity model to promote student exchanges in the ASEAN community.

b. Compare the student's achievement test between pretest and posttest after using activities with the model created.

c. Analyze the score of the students' satisfaction questionnaire on the model of activities to promote the exchange of students in the ASEAN community.

Fig 1 format to support an exchange students in ASEAN community

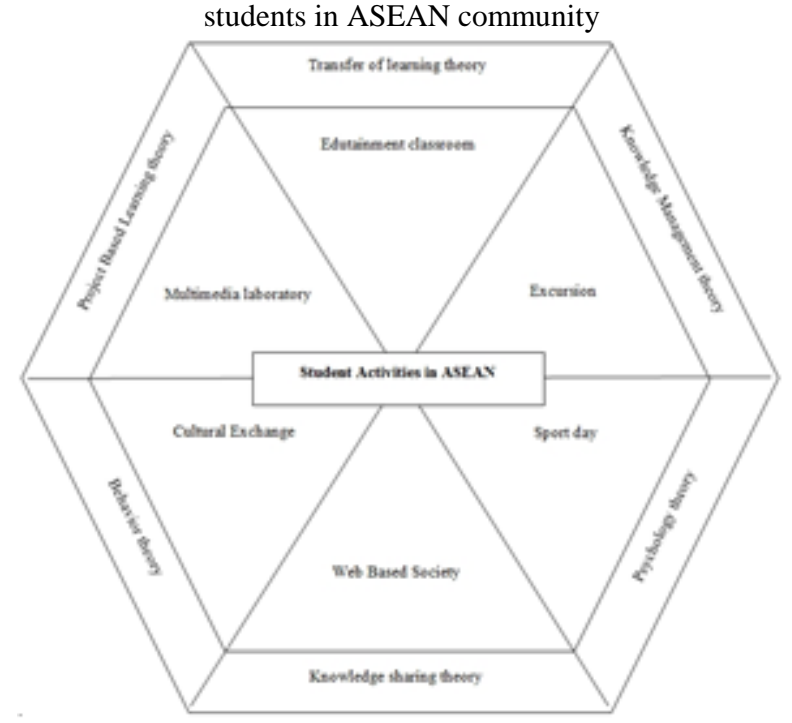

TABLE I SHOWS THE COMPARISON OF MEANS SCORES BETWEEN PRETEST AND POSTTEST SCORES ON THE FORMAT OF ACTIVITIES TO PROMOTE STUDENT EXCHANGES IN THE ASEAN COMMUNITY.

No. Full Score $\begin{gathered}\text { Means } \\ \text { score }\end{gathered} \quad$ S.D. $\quad t \quad$ Sig.(2-tailed)

Pretest $\quad 40 \quad 3.07$

49.74

0.00

Posttest $\quad 40 \quad 32.46 \quad 2.03$

Table 1 shows that the results of the activities model to support the undergraduate students in ASEAN community of. The table illustrated that the Means score of the pretest was 19.37 with the S.D. of 3.07. After the student joined the activity model support for exchange students in ASEAN, the Means score of posttest test was higher at 32.46, and the value of S.D. was 2.03. The t-test was 49.74 at the 0.05 level of significance before and after the study.

The results of the analysis of the level of satisfaction of undergraduate students who joined the activity model of the knowledge based learning activities at Rajamangala University of Technology Thanyaburi showed the highest level of satisfaction with the Means score of 4.90. The highest score of the satisfaction was 4.97 while the lowest score was 1.67. 


\section{CONCLUSION}

The emphasis on communication with the use of different languages should focus on the exchange activity model by providing an exchange of experiences in the study of internships among international students in ASEAN to create exchanging knowledge.

The knowledge around us which can be compared to "Knowing yourself, Knowing other"is the understanding of religion, culture, beliefs, because in society we live together and cannot depend on the only skill or knowledge for living. Therefore, these preparations cannot be prepared overnight, it takes time since the first day of the childhood.

Nowadays, the government tries attach the importance and strives to prepare for more changes such as the development of exchange activities in English language to prepare and promote inter-ethnic communication in ASEAN. It also requires training in communication and cultures as in an attempt to develop cooperation in ASEAN in the future.

\section{REFERENCES}

[1] Department of Trade Negotiations. , 2013, Fresh Graduate toward what is possible in the AEC. Retrieved on August 3rd. 2014. From (http://www.thai-aec.com/61

[2] Report from subcommittee on foreign workers escape the Senate. 2009, "Problems and solutions to migrant workers escaping into Myanmar", Bangkok, Committee on Labor and Social Welfare senate.

[3] Chernin Subshy, "Land Bridge: The Republic of Laos: Union of Myanmar Documentation of the Trade Issues Committee meeting", organized on 23 October2011, Thai Chamber of Commerce, 2011

[4] Chinnorn Boonyakiat, 2012 "Thai Education Preparation to step into the ASEAN community." Special Lecture Online, Retrieved on 23 July 2014 from http://www.chinnaworn.com

[5] Nathikan Raknak, 2009, "Development of instructional model based on learning concept to promote problem solving skills and mathematics reasoning and linking of Mathayomsuksa 1 students", Faculty of education, Chulalongkorn University.

[6] Songsak strains, 2014 Trends and frameworks. Of economic integration in the international economy and in Asia. 